\title{
DFT calculations of pentalenoquinones: towards the interception of 2-bromopentalene-1,5-dione
}

\author{
Taner Atalar, ${ }^{\mathrm{a}}$ Fatih Algı, ${ }^{\mathrm{a}, \mathrm{b}}$ and Metin Balci ${ }^{\mathrm{a}}$ * \\ ${ }^{a}$ Department of Chemistry, Middle East Technical University, 06531, Ankara, Turkey \\ ${ }^{b}$ Laboratory of Organic Materials, Department of Chemistry, Çanakkale Onsekiz Mart \\ University, 17100, Çanakkale, Turkey \\ E-mail: mbalci@metu.edu.tr
}

This paper is dedicated to Professor Udo H. Brinker on the occasion of his $65^{\text {th }}$ birthday

\begin{abstract}
To reveal the stability and the aromatic character of pentalenoquinones (PQs) 1-4 and the corresponding bromo derivatives (Br-PQs) 6-9, DFT calculations (B3LYP/6-311+G(d,p)) concerning the geometry optimization, total energy and nucleus independent chemical shift (NICS) values were performed. It was found that all of the compounds have planar geometry. As the energy difference between HOMO-LUMO energy levels $\left(\Delta \varepsilon=\varepsilon_{\text {LUMO }}-\varepsilon_{\text {HOMO }}\right)$ and total energies were considered for the pentalene family, the stability order was found to be $\mathbf{1}>\mathbf{2}>\mathbf{3}>$ $\mathbf{4}$ for PQs, and $\mathbf{6}>\mathbf{7}>\mathbf{8}>\mathbf{9}$ for Br-PQs. Furthermore 2-bromopentalene-1,5-dione (6) in solution was investigated and noted that it was too reactive to be isolated or even trapped.
\end{abstract}

Keywords: Pentalene, pentalenoquinones, DFT calculations

\section{Introduction}

Pentalenoquinones (PQs) 1-4, quinone derivatives of pentalene (5), may be defined as fully unsaturated derivatives of various isomeric bicyclo[3.3.0] octanediones and have fascinated scientists due to their extraordinary physical and chemical properties (Figure 1). For example, Delamere et al. have reported on the geometries, bond orders, chemical hardness, the NICS values and homodesmoric ring-opening reactions. ${ }^{1}$ Recently, Yavari and co-workers ${ }^{2}$ reported the structural optimization of PQs with semi-empirical and ab initio calculations, providing a picture of geometries of PQs from both structural and energetic points of view; and 1,5-PQ, 1, was calculated to be the most stable isomer, albeit elusive. 
<smiles>O=c1cc2ccc(=O)c-2c1</smiles>

1<smiles>O=c1cc2cc(Br)c(=O)c-2c1</smiles>

6

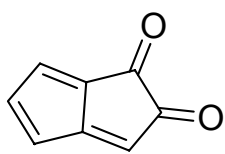

2

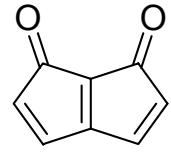

3<smiles>O=C1C=CC2=CC=CC12</smiles>

4<smiles>O=c1ccc2cc(Br)c(=O)c1=2</smiles>

8<smiles>O=c1ccc2c(Br)cc1=2</smiles>

9

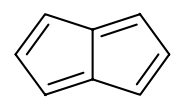

5<smiles>O=c1cc2cc(Br)cc-2c1=O</smiles>

7

\section{Figure 1}

Although the chemistry of PQs, such as $\mathbf{1}$, has been the subject of some theoretical studies, the extent of our present understanding regarding the stability, Diels-Alder and the (non)aromatic character of 1 is meager due to the lack of an extensive theoretical study as well as experimental evidence which demonstrates the existence of free $1{ }^{3}$ Herein we wish to report the results of our research in this field concerning DFT calculations geometry optimization, total energy and nucleus independent chemical shift (NICS) values ${ }^{4}$ for the pentalene family, 1-10. Furthermore, the fate of 2-bromopentalene-1,5-dione (6) in solution was investigated.

\section{Results and Discussion}

\section{Theoretical calculations}

We first ran DFT calculations for compounds 1-5. Geometry optimizations were performed at the level of B3LYP/6-311+G(d,p) ${ }^{5-7}$ to reveal at least a local minimum on the potential energy surface for each set of calculations, vibrational analyses were done (using the same basis set employed in the corresponding geometry optimizations). The normal mode analysis for each structure yielded no imaginary frequencies for the $3 N-6$ vibrational degrees of freedom, where $N$ is the number of atoms in the system. This indicates that the structure of each molecule corresponds to at least a local minimum on the potential energy surface. Figure 2 shows the optimized structures for compounds 1-5 and bond lengths in $\AA$, respectively. 


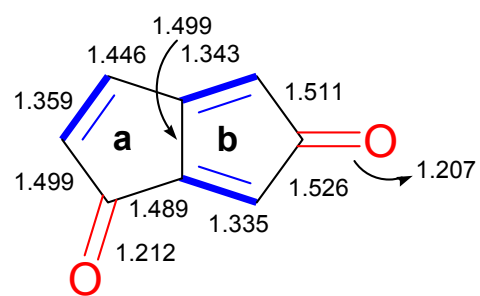

1

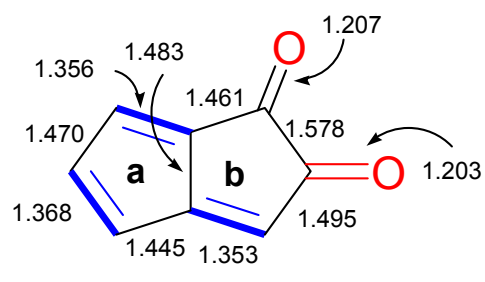

2

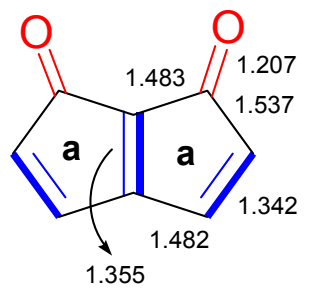

3
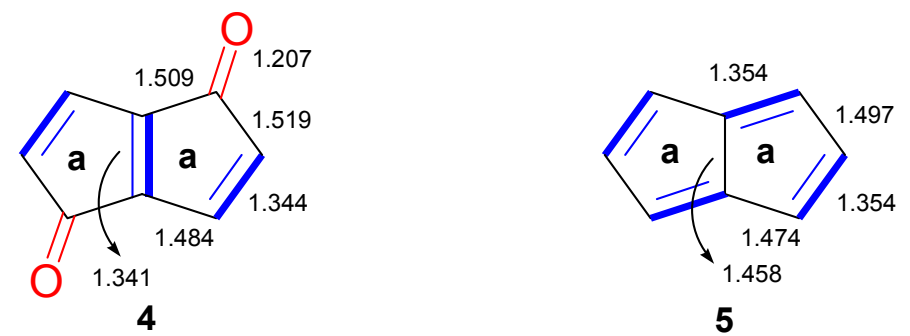

5

Figure 2. The geometry optimized structures of compounds 1-5 and the bond lengths in $\AA$ ( $a$ and $b$ indicate the ring for NICS calculations).

Table 1. HOMO and LUMO energies ( $\varepsilon$ in eV), NICS values (in ppm), point groups and dipole moments (in Debye) (B3LYP/6-311+G(d,p)) for the geometry optimized structures of compounds 1-10

\begin{tabular}{cccccccc}
\hline & \multicolumn{7}{c}{ NICS $(0)$} \\
\hline $\mathbf{1}$ & HOMO & LUMO & $\Delta \varepsilon$ & $\mathrm{a}$ & $\mathrm{b}$ & Point group & Dipole moment \\
$\mathbf{2}$ & -7.386 & -3.521 & 3.865 & 2.9 & 4.6 & $\mathrm{C}_{\mathrm{S}}$ & 4.032 \\
$\mathbf{3}$ & -6.903 & -3.729 & 3.174 & -0.4 & 6.9 & $\mathrm{C}_{\mathrm{S}}$ & 6.509 \\
$\mathbf{4}$ & -6.932 & -4.101 & 2.831 & 6.5 & & $\mathrm{C}_{2 \mathrm{v}}$ & 6.198 \\
$\mathbf{5}$ & -6.719 & -4.170 & 2.549 & 12.6 & & $\mathrm{C}_{2 \mathrm{~h}}$ & 0.000 \\
$\mathbf{6}$ & -5.515 & -2.940 & 2.575 & 24.3 & & $\mathrm{C}_{2 \mathrm{~h}}$ & 0.000 \\
$\mathbf{7}$ & -7.374 & -3.625 & 3.749 & 2.5 & 3.2 & $\mathrm{C}_{\mathrm{S}}$ & 3.429 \\
$\mathbf{8}$ & -7.059 & -3.906 & 3.153 & -2.7 & 6.9 & $\mathrm{C}_{\mathrm{S}}$ & 5.557 \\
$\mathbf{9}$ & -6.886 & -4.257 & 2.629 & 8.5 & 6.2 & $\mathrm{C}_{\mathrm{S}}$ & 6.120 \\
$\mathbf{1 0}$ & -6.657 & -4.361 & 2.296 & 11.2 & 9.2 & $\mathrm{C}_{\mathrm{S}}$ & 1.018 \\
\hline
\end{tabular}

For the optimized structures, HOMO (highest occupied molecular orbital) and LUMO (lowest unoccupied molecular orbital) energies ( $\varepsilon$ in $\mathrm{eV}$ ), dipole moments (in Debye) and point groups were listed in Table 1 . As the difference between HOMO-LUMO energy levels $(\Delta \varepsilon=$ $\varepsilon_{\mathrm{LUMO}}-\varepsilon_{\mathrm{HOMO}}$ ) was considered, the order was found to be $\mathbf{1}>\mathbf{2}>\mathbf{3}>\mathbf{4}$ for PQs.

In order to evaluate what effect a bromine atom would have on the energy profile of compounds 1-5, we performed DFT calculations at the same level for the corresponding bromo derivatives 6-10 (Fig. 3.). It was found that the presence of a bromine atom in the structure 
causes elongation or contraction of certain bonds (for example compare $\mathbf{1}$ and 6). When the difference between HOMO and LUMO energy levels $\left(\Delta \varepsilon=\varepsilon_{\text {LUMO }}-\varepsilon_{\text {HOMO }}\right)$ was considered, the order was found to be $\mathbf{6}>\mathbf{7}>\mathbf{8}>\mathbf{9}$ for bromo-PQs. Furthermore, we noticed that the insertion of bromine atom decreased the energy gap $(\Delta \varepsilon)$ between HOMO and LUMO.

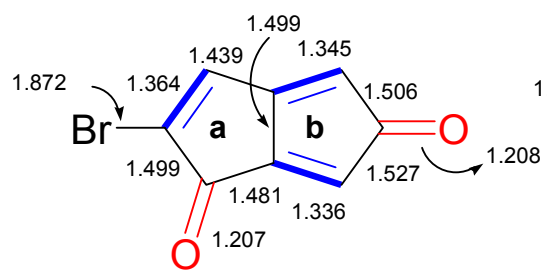

6

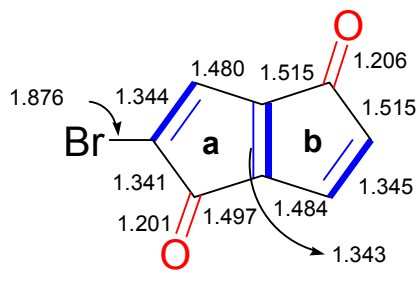

9

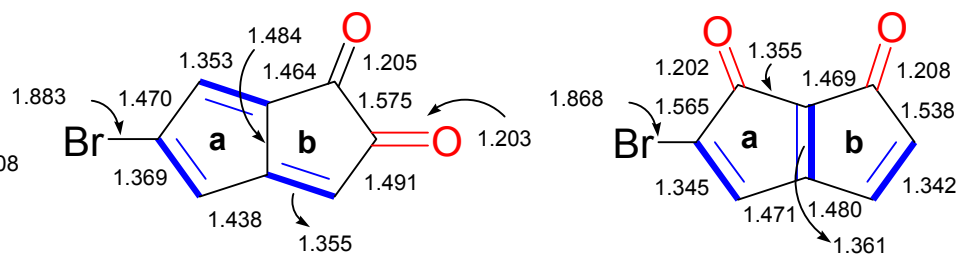

7

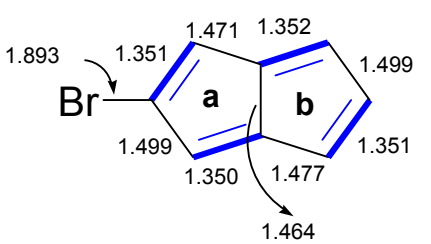

10

Figure 3. The geometry optimized structures of compounds 6-10 and the bond lengths in $\AA$ ( $a$ and $b$ indicate the ring for NICS calculations).

It is well established that Nucleus Independent Chemical Shift (NICS) is an indication of aromatic and/or anti-aromatic character for a given system. ${ }^{4}$ To get insight into the aromatic character of each member of the pentalene family, NICS values (in ppm) were calculated at B3LYP/6-311 G (d,p) level of theory based on the B3LYP/6-311 + G(d,p) optimized structures. NICS (0) calculations showed that there is no definite indication of aromatic and/or anti-aromatic character for PQs and Br-PQs. This result is consistent with previous findings in the literature. ${ }^{1}$ However, it is worth noting that the bromine atom insertion generally decreased the NICS (0) values especially in the case of ring a. For example, on the one hand for pentalene, the NICS (0) value was decreased from $24.3 \mathrm{ppm}$ to $21.1 \mathrm{ppm}$ (compare $\mathbf{5}$ and $\mathbf{1 0}$ in Table 1), while on the other hand, for 3 and its bromo derivative 8, the NICS (0) value was increased from 6.5 ppm to 8.5 ppm (Table 1). 
Table 2. Calculated energies of compounds 1-10

\begin{tabular}{ccccc}
\hline & Total Energy (a.u) & ZPE (kJ/mol) & Enthalpy (kJ/mol) & $\begin{array}{c}\text { Relative Enthalpy }^{\mathrm{a}} \\
(\mathrm{kJ} / \mathrm{mol})\end{array}$ \\
\hline $\mathbf{1}$ & -457.758800 & 251.712 & -1201573 & $0^{\mathrm{b}}$ \\
$\mathbf{2}$ & -457.758451 & 252.159 & -1201572 & $1^{\mathrm{b}}$ \\
$\mathbf{3}$ & -457.735980 & 249.971 & -1201515 & $58^{\mathrm{b}}$ \\
$\mathbf{4}$ & -457.733803 & 249.553 & -1201509 & $64^{\mathrm{b}}$ \\
$\mathbf{5}$ & -308.447479 & 287.935 & -809524 & - \\
$\mathbf{6}$ & -3031.299190 & 225.568 & -7958431 & $0^{\mathrm{c}}$ \\
$\mathbf{7}$ & -3031.299150 & 225.664 & -7958430 & $1^{\mathrm{c}}$ \\
$\mathbf{8}$ & -3031.276950 & 224.258 & -7958373 & $58^{\mathrm{c}}$ \\
$\mathbf{9}$ & -3031.272450 & 223.495 & -7958362 & $69^{\mathrm{c}}$ \\
$\mathbf{1 0}$ & -2881.989330 & 262.129 & -7566385 & - \\
\hline
\end{tabular}

${ }^{a}$ Relative enthalpies were calculated from the enthalphy values obtained at $25^{\circ} \mathrm{C}$ and 1 atm. ${ }^{b}$ These values were calculated relative to the most stable isomer $1{ }^{\mathrm{c}}{ }^{\mathrm{T}}$ These values were calculated relative to the most stable isomer 6.

To sum up the theoretical results, the lowest symmetry point group was found to be $\mathrm{C}_{\mathrm{s}}$ for the molecules and all of them have planar geometry. As the difference between HOMO-LUMO energy levels ( $\left.\Delta \varepsilon=\varepsilon_{\mathrm{LUMO}}-\varepsilon_{\mathrm{HOMO}}\right)$ was considered for the pentalene family 1-10, the order was found to be $\mathbf{1}>\mathbf{6}>\mathbf{2}>\mathbf{7}>\mathbf{3}>\mathbf{8}>\mathbf{5}>\mathbf{4}>\mathbf{1 0}>\mathbf{9}$. Generally, the high energy gap value resulting from the relatively high energy of LUMO and low energy of HOMO indicates that neither losing nor capturing an electron will occur easily and, thus the compound is expected to be stable. Table 2 indicates some calculated energies of species at the B3LYP/6-311+G(d,p) level of theory. All the results showed that the stability order is $\mathbf{1}>\mathbf{2}>\mathbf{3}>\mathbf{4}$ for PQs and $\mathbf{6}>\mathbf{7}>\mathbf{8}>\mathbf{9}$ for Br-PQs. The calculated energy difference between the most favorable and unfavorable species is 64 and $69 \mathrm{~kJ} / \mathrm{mol}$ for PQs and Br-PQs, respectively. In terms of total energy and enthalpy values, finding the stability order is similar to the stability order obtained in the case of frontier molecular orbital energy gaps. These theoretical results encouraged us to investigate the fate of 6 in solution, since it looks quite feasible among the others.

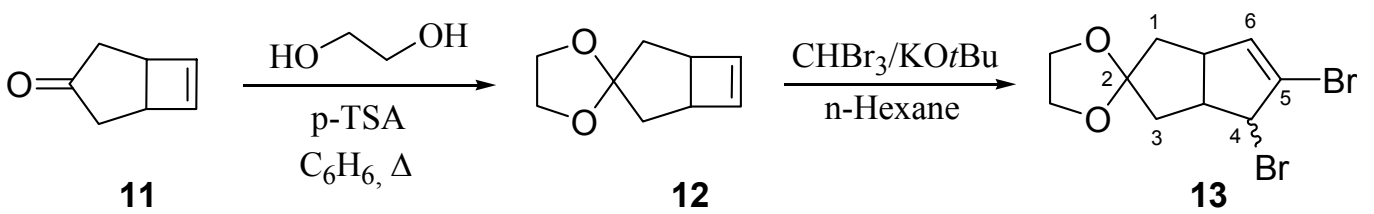

\section{Scheme 1}


In order to obtain the desired skeleton, we started with the known ketone 11. ${ }^{8}$ Dibromo carbene addition to the double bond after protection of the carbonyl moiety with ethylene glycol in the presence of acid, provided $\mathbf{1 3}$ (Scheme 1) whose structure was elucidated on the basis of NMR spectral data. Careful inspection of the ${ }^{1} \mathrm{H}-\mathrm{NMR}$ spectrum indicated the presence of two isomers (exo- and endo-) in a ratio of 3:1, respectively. The ${ }^{1} \mathrm{H}-\mathrm{NMR}$ spectrum of exo-13 shows five sets of signals. The olefinic proton (H-6) appear as doublet at $5.93 \mathrm{ppm}(J=2.1 \mathrm{~Hz})$ whereas the proton $\mathrm{H}-4$ appears as a broad singlet at $4.62 \mathrm{ppm}$. The protons of the ring junction $(\mathrm{H}-3 \mathrm{a}$ and $\mathrm{H}-6 \mathrm{a})$ give rise to multiplets between $3.50-3.00 \mathrm{ppm}$. A ten-line (see below) ${ }^{13} \mathrm{C}-\mathrm{NMR}$ spectrum is also in agreement with the structure.

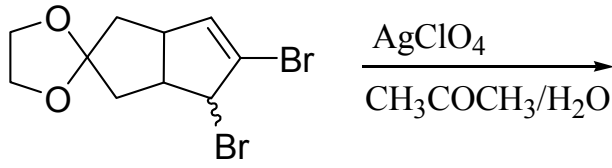

13

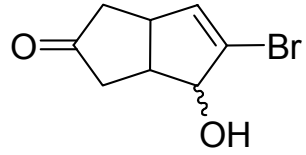

14

\section{Scheme 2}

Interestingly, when compound $\mathbf{1 3}$ was treated with $\mathrm{AgClO}_{4}$ in moist acetone, a mixture of hydroxy ketone 14 was the only isolated product and in $25 \%$ yield (Scheme 2). In an attempt to increase the yield of hydroxy ketone 14, we found that the reaction of 13 with NaOAc in HOAc provides compound $\mathbf{1 5}$ along with a minor product identified as $\mathbf{1 6}$ (Scheme 3). The ${ }^{1} \mathrm{H}-\mathrm{NMR}$ spectrum of 16 indicated two olefinic protons resonate at $6.83 \mathrm{ppm}$ (bs) and 5.79 (d, $J=1.8 \mathrm{~Hz}$ ). The proton at the ring junction appears at $3.55 \mathrm{ppm}$ as a triplet $(J=5.6 \mathrm{~Hz})$, whereas the methylenic protons appear as two different AB systems between 3.00-2.00 ppm. The ${ }^{13} \mathrm{C}-\mathrm{NMR}$ spectrum with eight signals was consistent with the assigned structure. Compound $\mathbf{1 6}$ arises from the competing elimination of $\mathrm{AcOH}$ under the given conditions. Formation of $\mathbf{1 6}$ could be suppressed by lowering the temperature.

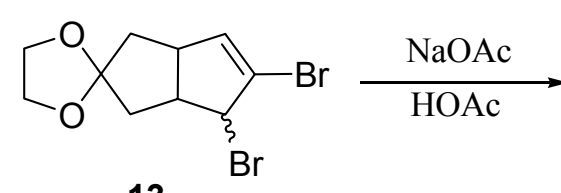

13

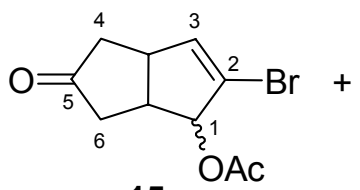

15

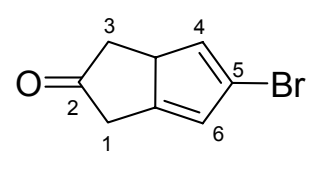

16

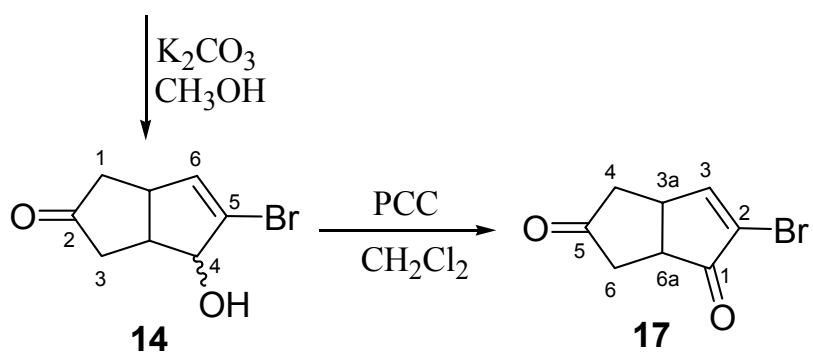

\section{Scheme 3}


Treatment of 15 with $\mathrm{K}_{2} \mathrm{CO}_{3}$ in $\mathrm{CH}_{3} \mathrm{OH}$ as the solvent followed by $\mathrm{PCC}$ oxidation of alcohol 14 in $\mathrm{CH}_{2} \mathrm{Cl}_{2}$, furnished the dione 17 in high yield (Scheme 3). In the ${ }^{1} \mathrm{H}-\mathrm{NMR}$ spectrum of $\mathbf{1 7}$, the proton $\mathrm{H}-3$ appears at $7.68 \mathrm{ppm}(\mathrm{d}, J=3.0 \mathrm{~Hz})$ as expected. However, the protons $\mathrm{H}-3 \mathrm{a}$ and H-6a resonate at $3.58(\mathrm{~m})$ and 3.17 (ddd, $J=11.9,6.6$ and $5.0 \mathrm{~Hz}$ ). On the other hand, the methylenic protons give rise to two sets of AB systems between 2.80-2.00 ppm. ${ }^{9}$

Our initial exploratory efforts directed towards the dehydrogenation of $\mathbf{1 7}$ involved the use of selenoxide elimination. ${ }^{10}$ Disappointingly, the reaction did not proceed with $\mathbf{1 7}$ being recovered, unaltered.

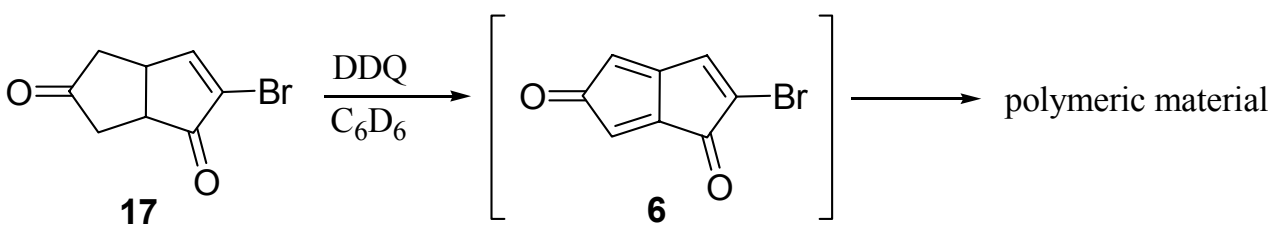

\section{Scheme 4}

Dehydrogenation of $\mathbf{1 7}$ with dicyanodichloro- $p$-benzoquinone (DDQ) ${ }^{11}$ in benzene for $12 \mathrm{~h}$ at ambient temperature indicated that ketone 17 was consumed but gave an insoluble polymeric material. Repeating the reaction either in the presence of furan or in benzene- $d_{6}$ under similar conditions gave the same results. This suggests, that 6 probably undergoes sequential intermolecular cycloaddition as soon as it is formed due to its high reactivity.

\section{Conclusions}

In summary, DFT calculations $(\mathrm{B} 3 \mathrm{LYP} / 6-311+\mathrm{G}(\mathrm{d}, \mathrm{p}))$ concerning the geometry optimization, total energy and nucleus independent chemical shift (NICS) values were performed in order to reveal the stability and aromatic character of PQs 1-4 and Br-PQs 6-9. It was found that all of them have planar geometry and if the difference between HOMO-LUMO energy levels $(\Delta \varepsilon=$ $\left.\varepsilon_{\mathrm{LUMO}}-\varepsilon_{\mathrm{HOMO}}\right)$ and total energies were considered, the stability order was found to be $\mathbf{1}>\mathbf{2}>\mathbf{3}$ $>4$ for PQs, and $\mathbf{6}>\mathbf{7}>\mathbf{8}>\mathbf{9}$ for Br-PQs. Furthermore, despite the quantum chemically indicated stability of PQ $\mathbf{6}$ when compared to other isomers, experimental results suggests that it is still too reactive to be isolated or even trapped in solution.

\section{Experimental Section}

General Procedures. Supplementary data concerning the details of the DFT calculations can be found in the online version via the internet. Geometry optimizations were performed at the level of B3LYP/6-311+G(d,p). The nucleus independent chemical shift (NICS) was used as a 
descriptor of aromaticity from the magnetic point of view. The index is defined as the negative value of the absolute magnetic shielding computed at ring centers or another interesting point of the system. In this study, NICS values were computed with GIAO B3LYP/6-311G (d,p) // B3LYP/6-311+G(d,p). NICS (0) was calculated at the geometrical center of the ring. For each set of calculations, vibrational analyses were done (using the same basis set employed in the corresponding geometry optimizations). The normal mode analysis for each structure yielded no imaginary frequencies for the $3 N-6$ vibrational degrees of freedom, where $N$ is the number of atoms in the system. This indicates that the structure of each molecule corresponds to at least a local minimum on the potential energy surface. All the calculations for the geometry optimizations and energies were performed using Gaussian 98 program package and Spartan 06 package programme.

Infrared spectra were recorded on a Mattson model 1000 FT-IR spectrometer. ${ }^{1} \mathrm{H}$ - and ${ }^{13} \mathrm{C}$ - NMR spectra were recorded on 400 and $100 \mathrm{MHz}$ spectrometers (Brucker/Avance), respectively. Column chromatography was performed on silica gel (60-200 mesh) from Merck Company. TLC was carried out on Merck $0.2 \mathrm{~mm}$ silica gel 60 F254 analytical aluminum plates. All the solvent purification was done as stated in the literature. ${ }^{12}$

Spiro[bicyclo[3.2.0]hept-6-ene-3,2'-[1,3]dioxolane] (12). Bicyclo[3.2.0]hept-6-en-3-one $\mathbf{1 1}^{13}$ $(5 \mathrm{~g}, 0.046 \mathrm{~mol})$, ethane-1,2-diol $(5.7 \mathrm{~g}, 0.09 \mathrm{~mol})$, catalytic amount of $p$-toluene sulphonic acid and anhydrous benzene $(50 \mathrm{~mL})$ were placed in a round-bottomed flask fitted with a Dean-Stark water separator and a reflux condenser. The reaction mixture was heated until no more, water collected. The reaction was also monitored by TLC. The mixture was cooled, the ethylene glycol layer was separated, and the benzene layer was washed succesively with saturated sodium bicarbonate solution and brine, dried over $\mathrm{MgSO}_{4}$. Removal of solvent gave $\mathbf{1 2}$ as a colorless oily liquid (5.6 g, $0.037 \mathrm{~mol})$ in a yield of $80 \%$. ${ }^{1} \mathrm{H}-\mathrm{NMR}\left(400 \mathrm{MHz}, \mathrm{CDCl}_{3}\right) \delta 6.0(\mathrm{~s}, 2 \mathrm{H}), 3.7-$ 3.9 (AA'BB' system, 4H), $3.2(\mathrm{t}, J=3.2 \mathrm{~Hz}, 2 \mathrm{H}), 1.8(\mathrm{bs}, 4 \mathrm{H}) .{ }^{13} \mathrm{C}-\mathrm{NMR}\left(100 \mathrm{MHz}, \mathrm{CDCl}_{3}\right) \delta$ 139.9, 119.5, 65.1, 63.6, 46.1, 38.8. IR $\left(\mathrm{CHCl}_{3}, \mathrm{~cm}^{-1}\right)$ 3035, 2933, 1741, 1425, 1334, 1273, 1177 , 1123, 1075, 1051, 1013, 762, 555. Anal. Calcd for $\mathrm{C}_{9} \mathrm{H}_{12} \mathrm{O}_{2}: \mathrm{C}, 71.03$; H, 7.95. Found: C, 70.90; H, 7.90 .

4',5'-Dibromo-3',3a',4',6a'-tetrahydro-1'H-spiro[1,3-dioxolane-2,2'-pentalene] (13). A solution of $9.17 \mathrm{~g}$ (36 mmol) $\mathrm{CHBr}_{3}$ in $n$-hexane $(20 \mathrm{~mL})$ was dropwise added to a mixture of 5 $\mathrm{g}(33 \mathrm{mmol})$ ketal 12 and $4.41 \mathrm{~g}(39 \mathrm{mmol}) \mathrm{KOBu}-\mathrm{t}$ in $n$-hexane $(80 \mathrm{~mL})$, with magnetically stirring at $0^{\circ} \mathrm{C}$ over a period of 6 hours. The organic layer was washed first with water and brine, dried over $\mathrm{MgSO}_{4}$. The residue was crystallized from $n$-hexane to give a mixture of exo- and endo-13 (3.95 g, $26 \mathrm{mmol}, 78 \%$ ) in a ratio of 3:1, respectively. NMR data of each isomer was extracted from the NMR spectrum of a mixture.

Exo-13: ${ }^{1} \mathrm{H}-\mathrm{NMR}\left(400 \mathrm{MHz}, \mathrm{CDCl}_{3}\right) \delta 5.93(\mathrm{~d}, J=2.1 \mathrm{~Hz}, 1 \mathrm{H}), 4.62(\mathrm{bs}, 1 \mathrm{H}), 3.79(\mathrm{bs}, 4 \mathrm{H})$, $3.36-3.28(\mathrm{~m}, 1 \mathrm{H}), 3.18(\mathrm{q}, J=8.4 \mathrm{~Hz}, 1 \mathrm{H}), 2.06-1.94(\mathrm{~m}, 2 \mathrm{H}), 1.64-1.55(\mathrm{~m}, 2 \mathrm{H}) .{ }^{13} \mathrm{C}-\mathrm{NMR}$ $\left(100 \mathrm{MHz}, \mathrm{CDCl}_{3}\right) \delta 140.5,122.7,117.4,65.2,64.5,64.0,50.9,46.3,41.3,39.1 . \mathrm{IR}\left(\mathrm{CHCl}_{3}\right.$, 
$\mathrm{cm}^{-1}$ ): 2885, 1742, 1602, 1430, 1334, 11092, 1089, 1016, 947, 795, 723, 436. Anal. Calcd for $\mathrm{C}_{10} \mathrm{H}_{12} \mathrm{Br}_{2} \mathrm{O}_{2}$ (endo-exo-mixture) : C, 37.07; H, 3.73; Br, 49.32. Found: $\mathrm{C}, 36.95 ; \mathrm{H}, 3.65$.

Endo-13: ${ }^{1} \mathrm{H}-\mathrm{NMR}\left(400 \mathrm{MHz}, \mathrm{CDCl}_{3}\right) \delta 5.77(\mathrm{~d}, J=2.1 \mathrm{~Hz}, 1 \mathrm{H}), 4.49(\mathrm{bs}, 1 \mathrm{H}), 3.79(\mathrm{bs}, 4 \mathrm{H})$, 3.36-3.28 (m, 1H), 3.00 (q, $J=7.5 \mathrm{~Hz}, 1 \mathrm{H}), 2.06-1.94(\mathrm{~m}, 2 \mathrm{H}), 1.64-1.55$ (m, 2H).

Reaction of 5-Bromo-1,3a,4,6a-tetrahydro-4-hydroxypentalen-2(1H)-one (14) with $\mathrm{AgClO}_{4}$. To a magnetically stirring solution of $1.41 \mathrm{~g}$ (6.79 mmol) $\mathrm{AgClO}_{4}$ in $40 \mathrm{ml}$ of acetone and 30 $\mathrm{mL}$ of distilled water was dropwise added a solution of $2 \mathrm{~g}(6.17 \mathrm{mmol})$ of 13 in $30 \mathrm{~mL}$ of acetone at room temperature. The mixture was further stirred for 2 hours and precipitated $\mathrm{AgBr}$ was filtered off. The solution was extracted with ether $(3 \times 100 \mathrm{~mL})$, and combined organic phases were washed with brine, dried over $\mathrm{MgSO}_{4}$. After removal of solvent with a rotary evaporator, the alcohol $14(0.34 \mathrm{~g}, 1.5 \mathrm{mmol})$ was obtained in a yield of $25 \%$.

Acetylation of 13. $5 \mathrm{~g}$ (15.4 mmol) of $\mathbf{1 3}$ and $2.3 \mathrm{~g}$. (16.9 mmol) of NaOAc were dissolved in 15 $\mathrm{mL}$ of glacial acetic acid. The mixture was heated up to reflux for 14 hours. Then the mixture was washed with saturated $\mathrm{NaHCO}_{3}$, and extracted with ether $(3 \times 30 \mathrm{~mL})$, dried over $\mathrm{MgSO}_{4}$, the solvent was evaporated. Column chromatography on silica gel with $3 \%$ ethyl acetate $n$-hexane as eluent gave compound 15 (3.12 g, $12 \mathrm{mmol}, 78 \%)$, and 16 as a single isomer (0.51 g, $2.5 \mathrm{mmol}$, $16 \%)$.

2-Bromo-5-oxo-1,3a,4,5,6,6a-hexahydro-pentalen-1-yl-acetate (15). Colorless oily liquid, ${ }^{1} \mathrm{H}$ NMR $\left(400 \mathrm{MHz}, \mathrm{CDCl}_{3}\right) \delta 6.10(\mathrm{~d}, J=1.9 \mathrm{~Hz}, 1 \mathrm{H}), 5.33(\mathrm{bs}, 1 \mathrm{H}), 3.60(\mathrm{~m}, 1 \mathrm{H}), 3.33-3.39(\mathrm{~m}$, $1 \mathrm{H}), 2.82$ (m, A part of AB system, 1H), 2.61 (dd, B part of AB system, $J=10.8-19.3 \mathrm{~Hz}, 1 \mathrm{H})$, $2.42(\mathrm{dd}, \mathrm{A}$ part of AB system, $J=10.1-19.0 \mathrm{~Hz}, 1 \mathrm{H}), 2.18(\mathrm{~m}, \mathrm{~B}$ part of AB system), 2.06 (s, 3H). ${ }^{13} \mathrm{C}-\mathrm{NMR}\left(100 \mathrm{MHz}, \mathrm{CDCl}_{3}\right) \delta$ 216.6, 170.9, 141.4, 122.1, 87.3, 44.9, 42.9, 42.0, 38.2, 21.3. IR $\left(\mathrm{CHCl}_{3}, \mathrm{~cm}^{-1}\right): 2979,2958,2916,2867,2846,2063,1749,1630,1455,1399,1371$, 1231, 1161, 1057, 1022, 812, 735, 651. Anal. Calcd for $\mathrm{C}_{10} \mathrm{H}_{11} \mathrm{BrO}_{3}: \mathrm{C}, 46.36 ; \mathrm{H}, 4.28 ; \mathrm{Br}$, 30.84. Found: C, 46.27; H, 4.22.

3-Bromo-3,3a,-dihydro-1H-pentalen-2-one (16). Colorless liquid, ${ }^{1} \mathrm{H}-\mathrm{NMR}\left(400 \mathrm{MHz}, \mathrm{CDCl}_{3}\right)$ $\delta 6.83(\mathrm{bs}, 1 \mathrm{H}), 5.79(\mathrm{~d}, J=1.8 \mathrm{~Hz}, 1 \mathrm{H}), 3.55(\mathrm{t}, J=5.6 \mathrm{~Hz}, 1 \mathrm{H}), 3.00$ (dd, A part of AB system, $\mathrm{J}=7.3-16.8 \mathrm{~Hz}, 1 \mathrm{H}), 2.68$ (m, B part of first AB system and A part of the second AB system, $2 \mathrm{H}), 2.34$ (dd, B part of the second AB system, $J=5.1-17.1 \mathrm{~Hz}, 1 \mathrm{H}) .{ }^{13} \mathrm{C}-\mathrm{NMR}(100 \mathrm{MHz}$, $\left.\mathrm{CDCl}_{3}\right) \delta 208.5,154.2,142.2,129.8,118.0,47.7,45.1,41.9 . \mathrm{IR}\left(\mathrm{CHCl}_{3}, \mathrm{~cm}^{-1}\right): 2968,1734$, 1604, 1584, 1266, 1108, 899, 812, 695. Anal. Calcd for $\mathrm{C}_{8} \mathrm{H}_{7} \mathrm{BrO}$ : C, 48.27; H, 3.54. Found: C, 48.20; H, 3.47 .

5-Bromo-1,3a,4,6a-tetrahydro-4-hydroxypentalen-2(1H)-one (14) via hydrolysis $1.07 \mathrm{~g}(7.72$ mmol) unhydrous $\mathrm{K}_{2} \mathrm{CO}_{3}$ and $2 \mathrm{~g}(7.72 \mathrm{mmol})$ of 15 were dissolved in $30 \mathrm{~mL}$ of $\mathrm{CH}_{3} \mathrm{OH}$ at room temperature. The reaction was monitored by TLC. After 1 hour, mixture was extracted with ethyl acetate $(3 \times 30 \mathrm{~mL})$, combined organic layers were dried over $\mathrm{MgSO}_{4}$, and the solvent was removed to give alcohol $14\left(1.50 \mathrm{~g}, 7.0 \mathrm{mmol}\right.$, ) in a yield of $90 \% .{ }^{1} \mathrm{H}-\mathrm{NMR}\left(400 \mathrm{MHz}, \mathrm{CDCl}_{3}\right) \delta$ 6.07 (d, $J=1.7 \mathrm{~Hz}, 1 \mathrm{H}), 6.05$ (d, $J=2.1 \mathrm{~Hz}, 1 \mathrm{H}), 4.77$ (d, $J=7.3 \mathrm{~Hz}, 1 \mathrm{H}), 4.47$ (bs, 1H), 3.60 $(\mathrm{m}, 1 \mathrm{H}), 3.30(\mathrm{~m}, 1 \mathrm{H}), 3.20(\mathrm{~m}, 1 \mathrm{H}), 3.00(\mathrm{~m}, 1 \mathrm{H}), 2.70-2.10(\mathrm{~m}, 4 \mathrm{H}) .{ }^{13} \mathrm{C}-\mathrm{NMR}(100 \mathrm{MHz}$, $\left.\mathrm{CDCl}_{3}\right) \delta 218.1,135.9,126.4,85.9,45.9,44.0,43.1,37.3 . \mathrm{IR}\left(\mathrm{CHCl}_{3}, \mathrm{~cm}^{-1}\right): 3399,2921,2847$, 
1732, 1613, 1398, 1314, 1165, 1058, 822. Anal. Calcd for $\mathrm{C}_{8} \mathrm{H}_{9} \mathrm{BrO}_{2}$ : C, 44.27; H, 4.18. Found: C, $44.21 ; \mathrm{H}, 4.02$.

2-Bromo-3a,4,6,6a-tetrahydro-pentalene-1,5-dione (17). To a magnetically stirring solution of $2.7 \mathrm{~g}(12.6 \mathrm{mmol}) \mathrm{PCC}$ in $30 \mathrm{~mL} \mathrm{CH} \mathrm{Cl}_{2}$ at $0{ }^{\circ} \mathrm{C}$, was dropwise added a solution of $2.50 \mathrm{~g} \mathrm{(11.5}$ mmol) of alcohol 14 in $20 \mathrm{~mL} \mathrm{CH}_{2} \mathrm{Cl}_{2}$. After stirring for additional 5 hours at RT, the reaction mixture was filtered off through a short silica gel column by eluting with $\mathrm{CH}_{2} \mathrm{Cl}_{2}$ to give $\mathbf{1 7}$ as a colorless liquid (2.13 g, $10.5 \mathrm{mmol}, 92 \%) .{ }^{1} \mathrm{H}-\mathrm{NMR}\left(400 \mathrm{MHz}, \mathrm{CDCl}_{3}\right) \delta 7.68(\mathrm{~d}, J=3.0 \mathrm{~Hz}, \mathrm{H}-$ 6), 3.62-3.56 (m, H-3a), 3.17 (ddd, $J=11.9,6.6$ and $5.0 \mathrm{~Hz}, \mathrm{H}-6 \mathrm{a}$ ), 2.80 (m, A parts of the two AB systems overlapped, $2 \mathrm{H}$ ), 2.40 (dd, B part of the AB system, $J=19.5$ and $3.8 \mathrm{~Hz}, 1 \mathrm{H}$ ), 2.15 (dd, B part of the AB system, $J=18.8$ and $4.2 \mathrm{~Hz}, 1 \mathrm{H}) .{ }^{13} \mathrm{C}-\mathrm{NMR}\left(100 \mathrm{MHz}, \mathrm{CDCl}_{3}\right) \delta 212.7$, 201.1, 162.8, 127.1, 44.1, 41.1 (2C), 40.2. IR $\left(\mathrm{CHCl}_{3}, \mathrm{~cm}^{-1}\right):$ 1738, 1274, 1259, 909, 762, 747. Anal. Calcd for $\mathrm{C}_{8} \mathrm{H}_{7} \mathrm{BrO}_{2}$ : C, 44.68; H, 3.28; $\mathrm{Br}, 37.16$. Found: $\mathrm{C}, 44.45 ; \mathrm{H}, 3.20$.

Treatment of 17 with DDQ. To a magnetically stirring solution of solution of 17 (200 mg, 1 $\mathrm{mmol}$ ) in $5 \mathrm{~mL}$ benzene was dropwise added a solution of DDQ (250 mg, $1.1 \mathrm{mmol})$ in $5 \mathrm{~mL}$ benzene. After total consumption of starting ketone (12 h, TLC), the solvent was removed under reduced pressure to give the polymeric compound. The same procedure was also repeated both in the presence of furan and $\mathrm{C}_{6} \mathrm{D}_{6}$ to give the same result.

\section{Acknowledgements}

The authors are indebted to TUBITAK (Scientific and Technological Research Council of Turkey), Department of Chemistry at Middle East Technical University) and TUBA (Turkish Academy of Sciences) for their financial support of this work.

\section{References}

1. Delamere, C.; Jakins, C.; Lewars, E. Can. J. Chem. 2001, 79, 1492.

2. Yavari, I.; Zabarjad-Shiraz, I.; Dehghan, S.; Roohi, H.; Shiri, M. J. Mol. Str. (Theochem) 2002, 589, 459.

3. (a) For phenyl derivative of quinone 3 see: Gavina, F.; Costero, A. M.; Luis, S. V. J. Org. Chem. 1984, 49, 4616. (b) For quinone 4 see: Gavina, F.; Costero, A. M.; Gonzales, A. M.; Luis, S. V. J. Org. Chem. 1987, 52, 2997.

4. (a) Schleyer, P. v. R.; Maerker, C.; Dransfeld, A.; Jiao, H.; Hommes, N. J. R. v. E. J. Am. Chem. Soc. 1996, 118, 6317. (b) Jiao, H.; Schleyer, P. v. R. Angew. Chem., Int. Ed. Engl. 1996, 35, 2383. (c) Subramanian, G.; Schleyer, P. v. R.; Jiao, H. Angew. Chem., Int. Ed. Engl. 1996, 35, 2638. (d) Jiao, H.J; Schleyer, P. v. R.; Mo, Y.; McAllister, M. A.; Tidwell, T. T. J. Am. Chem.Soc. 1997, 119, 7075. (f) Balci, M.; McKee, M. L.; Schleyer, P. v. R. J. Phys. Chem. A 2000, 104, 1246. 
5. Becke, A. D. J. Chem. Phys. 1993, 98, 5648.

6. Becke, A. D. Phys. Rev. A 1998, 38, 3098.

7. Lee, C.; Yang, W.; Parr, R. G. Phys. Rev. B 1988, 37, 785.

8. Dauben, W. G.; Cargill, R. L. Tetrahedron 1961, 12, 186.

9. Balci, M. Basic H-1 and C-13 NMR Spectroscopy, Elsevier: New York, 2005; p 394.

10. Marx, J. N.; Cox, J. H.; Norman, L. R. J. Org. Chem. 1972, 37, 4489.

11. Walker, D.; Hiebert, J. D. Chem. Rev. 1967, 67, 153.

12. Furniss, B. S.; Hannaford, A. C.; Smith, G. S. W.; Tatchell, A. R. In Vogel's Textbook of Practical Organic Chemistry, $5^{\text {th }}$ Edition, Wiley, 1991-1994.

13. Dauben, W. G.; Cargill, R. L. Tetrahedron 1961, 12, 186. 